\title{
“TRANSIÇÁO” E “HISTÓRIA” NA JUSTIÇA TRANSICIONAL
}

\author{
“TRANSITION” AND "HISTORY” WITHIN TRANSITIONAL JUSTICE
}

\author{
Gabriel Rezende de Souza Pinto ${ }^{\mathrm{I}}[$
}

${ }^{\mathrm{I}}$ Instituto Brasiliense de Direito Público (IDP), Brasília, DF, Brasil. Doutor em Filosofia. E-mail: grezendesou@gmail. com

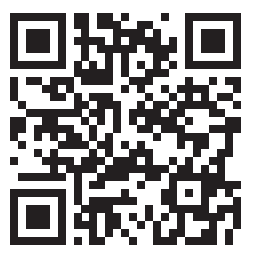

DOI: http://dx.doi. org/10.31512/rdj.v20i37.48

Recebido em: 27.07.2019

Aceito em: 05.04.2020

\begin{abstract}
Resumo: Este artigo aborda a relação entre o campo da Justiça Transicional e a historicidade. Mais especificamente, argumenta-se que os próprios conceitos com os quais a Justiça Transicional opera são herdados de um paradigma transitológico, que se caracteriza por seu arcabouço teórico anistórico e a-contextual. A história é limitada a um papel meramente funcional, e serve ao só propósito de consolidar uma nova democracia. Apontarei os problemas dessa concepção, especialmente no que diz respeito à violação de direitos fundamentais. No lugar de uma concepção instrumental da história, demonstrarei a necessidade de incorporar elementos hermenêuticos à justiça de transição.
\end{abstract}

Palavras-chave: Justiça de Transição. Transitologia. História. Democracia. Constitucionalismo.

\begin{abstract}
This paper addresses the connection between the field of Transitional Justice and historicity. More specifically, it argues that Transitional Justice operates with concepts inherited from the transitions paradigm an ahistorical and non-contextual theoretical framework. History is limited to a mere functional role, and it serves the only purpose of consolidating a new democracy. I shall point out the problems with this conception, especially in terms of its disregard to fundamental rights. Instead of an instrumental conception of history, I will demonstrate the necessity of incorporating some hermeneutical elements to transitional justice.
\end{abstract}

Keywords: Transitional Justice. Transitology. History. Democracy. Constitutionalism 


\section{Introduçáo}

O que dizemos ao enunciar o sintagma "justiça de transição"? Esta pergunta soará enfadonha aos ouvidos de muitos: parecerá a uns uma excessiva compulsão filosófica, espécie de obsessão pelo "o que é?"; a outros atestará flagrante incompreensão, claro atraso diante de um determinado aglomerado de reflexóes que há muito superou o problema dos contornos e das definiçóes auto-referenciais. O que estaria agora em jogo, diriam estes, é o momento de atualização de virtualidades, de uso e implementação dos instrumentais teóricos disponíveis.

Entretanto, aquela pergunta inicial permanece sendo curiosa. Assumamos, inicialmente, que o termo "justiça de transição" se refira às relaçóes havidas entre o direito e as transições políticas para regimes mais democráticos. "Justiça de transição" designa, pois, tanto um objeto-problema quanto um campo de estudos, uma regiáo do saber humano. Esta definição preliminar nos permite imaginar que a justiça transicional possui, necessariamente, um elemento retrospectivo. $\mathrm{O}$ retorno ao passado é exigido não apenas para atribuir devidamente responsabilidades de ordem civil e penal aos ilícitos ligados ao regime anterior, mas também para devidamente projetar a diferença entre democracia e autoritarismo.

Neste artigo, discute-se a relação entre justiça de transição e história. Em um primeiro momento, reconstrói-se os passos formativos da justiça transicional e as querelas já ali existentes com o saber histórico em sentido estrito. Em seguida, debate-se a forma muito particular com que cientistas políticos ligados à chamada "transitologia" definiram um paradigma anistórico de compreensão das transiçóes políticas. $\mathrm{Na}$ seção final, investiga-se a herança da transitologia sobre a justiça de transição, apontando-se os diversos problemas que podem daí decorrer.

\section{Transição e história}

Em trabalho seminal sobre o tema, Paige Arthur oferece o que se pode considerar como a melhor abordagem histórica sobre o uso do sintagma "transitional justice”. Dialogando com os antecedentes teóricos, as necessidades factuais e as opções normativas que se condensaram na cunhagem do campo, Arthur enxerga na publicação de Transitional Justice: how emerging democracies reckon with former regimes, obra organizada por Neil Kritz, o evento mais significativo da propagação da justiça transicional (2009, p. 330). Pela primeira vez, os resultados de uma série de congressos e seminários, textos esparsos, artigos, pesquisas acadêmicas e depoimentos relacionados à militância política e aos direitos humanos eram reunidos sob uma única rubrica. A justiça de transição, entretanto, fora mais do que um mero agregador linguístico: ela era ali e continua a ser um horizonte, uma ideia reguladora. Kritz, neste sentido, é mais do que um simples 
organizador: melhor seria dizer que ele é o concretizador da temática, é aquele que lhe dá uma portada singular ao erguer os pilares fundamentais que a estruturam, a saber: sançóes penais, sançóes administrativas, acesso a documentos e reconhecimento do passado e reparaçóes, restituiçóes e reabilitações (KRITZ, p. xxi et seq.).

Em sua resenha do referido livro para o prestigioso New York Review of Books, Timothy Garton Ash verá com bastante desconfiança a proposta de uma justiça de transição. Já em 1998 - o primeiro volume do Transitional Justice de Kritz é de 1995 -, Ash, historiador de formação, criticará duramente a total ausência de reflexão histórica na proposta. Dirá ele que:

Há vasta literatura, escrita principalmente por cientistas políticos, juristas e ativistas de direitos humanos, ao invés de historiadores, vendo em geral o passado como um elemento em "transições" de ditaduras para-assim se espera - democracias consolidadas. Três inestimáveis e grossos volumes, muito limitadamente intitulados Transitional Justice, documentam o modo com o qual se lidou com o passado em diferentes partes do mundo até 1995 (ASH, 1998). ${ }^{1}$

A crítica de Ash é aquela de um historiador inconformado com o modo relapso com que o passado era ali tratado. Ao final da resenha, após comentar rapidamente as demais formas de tratamento do passado (sanções criminais, depuraçóes, etc.) sua conclusão não é outra, senão a de que o profissional da história é o mais apto a fazer justiça ao passado; ele está de posse do savoir-faire necessário à empreitada de percorrer seus riscos - riscos estes que, tomados sem os devidos cuidados, "pode[m] arruinar vidas" (ASH, 1998). ${ }^{2}$ Afinal, é o próprio estatuto da história e, num certo sentido, da historicidade e de seu acesso, que estão permanentemente em questão e em tensão aos olhos de Ash. Mais do que a exclusão do historiador do lugar clássico de fixação de sua disciplina e de seu saber, as reservas feitas à transitional justice de Kritz se referem à estreiteza com que o passado é revisitado por meio da ciência política, do direito e do ativismo em direitos humanos. Caberia perguntar, portanto, a que fim se orienta a investigação do passado na justiça transicional? Qual o sentido desta revisita? Que significado adquire uma investigação do passado que não se proponha a ser uma investigação historiográfica feita por historiadores?

Paige Arthur é muito feliz ao mostrar a mais intrigante ausência na reunião de textos feita por Kritz. Não há nenhum exagero em se considerar que o Historikerstreit, a famosa querela dos historiadores, ocorrida na República Federal da Alemanha ao final da década de 80 - nos estertores, portanto, da própria Guerra Fria -, representara uma dais maiores instâncias de discussão sobre a relação entre justiça e passado no séc. XX. Note-se que ela ocorria em paralelo aos seminários e estudos que desembocaram na transitional

1 No original: "There is already a vast literature, mostly written by political scientists, lawyers, and human rights activists, rather than historians, and mainly viewing the past as an element in "transitions" from dictatorship to - it is hoped consolidated democracy. Three invaluable, thick volumes, too narrowly entitled Transitional Justice, document the way the past has been dealt with in different parts of the world up to 1995 ".

2 No original: "Can ruin lives". 
justice, o que torna ainda mais difícil a compreensão do por quê de tal negligência. Afinal, os temas são próximos demais para que se consiga sequer separá-los com nitidez. Quando os historiadores alemães mais orientados à esquerda do espectro político reagiam veementemente à retórica pergunta de Ernst Nolte - "Não era o 'Arquipélago Gulag' anterior a 'Auschwitz'? Não fora o morticínio de classe bolchevique lógica e factualmente preliminar ao morticínio de raça nacional-socialista?” (NOLTE, 1986) ${ }^{3}$ - não estavam eles também interessados num acerto de contas com o passado, prospectando um modo de vida mais democrático? Pois bem, se este debate não se encontrava presente no conjunto teorético informativo da justiça de transição, há que se suspeitar que ambos não comungavam uma mesma orientação. Essa é a opinião de Arthur aqui compartilhada:

Esta omissão nos diz algo a respeito da concepção de Kritz (e outros) sobre a justiça de transição. Dos quarenta e dois textos reunidos no panorama geral temático da justiça de transição feito por Kritz, nenhum foi escrito por historiadores e o debate histórico alemão merece apenas uma singela referência. A razão para a omissão não é tão difícil de ser adivinhada: historiadores simplesmente não estavam envolvidos na produção do livro de Kritz, tampouco desempenharam um papel de relevo nas discussóes dos temas identificados por Kritz - e implicitamente aceito pela maioria como informadores do conteúdo conceitual da justiça de transição. Ao invés de acertar contas com as complexidades históricas (como se pode esperar de um esforço para lidar com o passado), a justiça de transição foi apresentada como profundamente envolta em problemas políticos que eram jurídico-institucionais e, relativamente, de curto-prazo por natureza. Tão claramente de curto-prazo que, de fato, eles poderiam ser resolvidos de modo específico durante o período de "transição" (ARTHUR, 2009, p. 333). ${ }^{4}$

No artigo que introduz o primeiro volume de seu Transitional Justice, Kritz deixa claro que o papel da história em períodos de transição é adversarial ou conflitivo. Isso significa, para ele, não a necessidade de se engajar numa luta pelo desvelamento da história cuja dimensão se daria num aspecto constitutivo-existencial, mas de definir uma correlação de forças que permitiria atribuir sentidos históricos visando à estabilidade do regime. Partindo do exemplo do negacionismo, ele afirmará que "se deixadas incontestes, estas pretensões podem minar o novo governo e fortalecer a mão daqueles que estáo decididos a dar de novo o poder ao antigo regime" (KRITZ, 1995, p. xxvi) no parágrafo seguinte ele ainda arrematará: “vê-se cada vez mais o estabelecimento de um

3 No original: "War nicht der Archipel Gulag” ursprünglicher als "Auschwitz"? War nicht der "Klassenmord” der Bolschewiki das logische und faktische Prius des Rassenmords der Nationalsozialisten?"

4 No original: "This omission tells us something about Kritz's (and others') conception of transitional justice. Of the forty-two texts gathered in Kritz's thematic overview of transitional justice (Vol. 1), none were written by historians, and the German historians' debate merits only a single passing reference. The reason for the omission is not hard to guess: historians simply were not involved in the production of Kritz's book, nor did they play an important role in discussions on the themes identified by Kritz—and implicitly accepted by most—as providing the conceptual content for transitional justice. Instead of "coming to terms" with historical complexities (as one might expect in an effort to deal with "the past"), transitional justice was presented as deeply enmeshed with political problems that were legal-institutional and, relatively, short-term in nature. So short-term, in fact, that they could be dealt with specifically during a 'transitional' period".

5 If left unconstested, these claims may undermine the new government and strengthen the hand of those determined to return the former regime to power. 
relato completo e oficial do passado como um elemento importante para uma transiçáo democrática exitosa” (KRITZ, 1995, p. xxvi). ${ }^{6}$ Fica claro que o regime democrático é o ideal regulador e a história um dos elementos idôneos a realizá-lo em sua inteireza. Em outras palavras, a história é vista como campo de batalha a ser dominado para garantir a força simbólica do novo regime - o que compreende a obtenção de apoio popular, legitimidade internacional e esvaziamento da força institucional dos partidários do regime ditatorial.

A questão que se coloca diante deste horizonte é menos a de saber que tipo de compreensão a justiça transicional esboça da história, e mais a de compreender o plexo de axiomas que a projetam como campo auto-referencial. Em entrevista a Paige Arthur, Juan Méndez, histórico ativista dos direitos humanos e presidente emérito do International center for transitional justice, e José Zalaquett, outra figura emblemática da luta pelos direitos humanos, ex-membro do governo Allende, lembram-se que o termo "transição" fora tomado de empréstimo das pesquisas em Ciência Política que se desenvolveram a partir de finais da década de 1970. Ambos participaram ativamente da série de Conferências ocorridas entre 1988 (State Crimes: punishment or pardon - Aspen Institute) e 1994 (Dealing with the past - África do Sul) e dão conta de que o referencial teórico era mesmo aquele da já clássica obra Transitions from Authoritarian Rule de Guillermo O’Donnell e Philippe Schmitter. Reconhecê-lo, entretanto, não significa assumir uma causalidade simples entre a chamada transitologia e a Justiça de Transição. O próprio Méndez parece se recusar a fazer uma tal passagem sem mediaçóes ao sustentar que o atual espectro principiológico dessa última disciplina não está restrito “(...) a um momento de câmbio de regime [político] num dado país” (MÉNDEZ, 2009, p. 157). ${ }^{7}$ Parece mais profícuo pensar em termos de um "paradigma das Transiçóes”, como quer Arthur (2009, p. 337) ou, ainda, uma vaga das transiçóes, num sentido que congregaria fenômenos político-sociais e linguagem ordinária, por um lado, e senda teorética por outro. De fato, o que há é uma espécie de pano de fundo compartilhado no qual os conceitos ordinário e científico de transição - irredutíveis um ao outro, ainda que coparticipem os motivos que ensejam a homonímia - podem existir, adquirir relevância e ascender, em seguida, à posição hegemônica na esfera político-social e à autoridade científica no mundo acadêmico. É de conhecimento geral o modo como, no princípio da década de 1980, o presidente norte-americano Ronald Reagan e George Shultz “(...) referiamse regularmente à 'Revolução democrática global'” (CAROTHERS, 2002, p. 6) ${ }^{8}$ para mobilizar o capital ideológico das mudanças de regime político ao redor do mundo. Há sérias dúvidas sobre o quão influente teria sido a nascente transitologia sobre as políticas

6 No original: "Establishing a full, official accounting of the past is increasingly seen as an important element to a successful democratic transition".

7 No original: “(...) a moment of regime change in a given country".

8 No original: “(...) were referring regularly to "the worldwide democratic revolution." 
de Estado encampadas pelos Estados Unidos da América no período; é provável que ela tenha servido como um léxico de interesses, e não como mola propulsora das relaçóes internacionais. De toda sorte, perfila-se com mais ou menos rigidez o nível situacional em que se dá este contrato de fala, de modo que os "participantes de uma enunciação devem aceitar tacitamente certo número de princípios que tornam possível a troca, e um certo número de regras que a controlam” (MAINGUENEAU, 2006, p. 35): o paradigma da transição acaba por definir seu objeto e, num certo sentido, altera profundamente o conteúdo dos fenômenos por ele apreendidos.

\section{0 paradigma da transitologia como definidor de um sentido para a história das transiçóes}

De modo muito esquemático, é possível caracterizar a transitologia como o movimento teórico surgido já na década de 70 - sobretudo ao final dela - cujo foco residia na passagem à democracia de países que viviam sob um regime autoritário. Mobilizando os conceitos de transiçáa - o intervalo entre um regime autoritário e a tomada completa de poder pelo regime que venha a sucedê-lo (O’DONNELL, SCHMITTER, 1986) - e democratização - "momento em que a incerteza sobre os resultados do jogo político e a força reguladora de regras universais se impuseram novamente sobre o poder de um ator único" (AVRITZER; COSTA, 2004, p. 703) -, autores como Dankwart Rustow (1970), Samuel Huntignton (1991), Juan Linz e Alfred Stepan (1996), além dos já citados O’Donnell e Schmitter empreenderam diversos estudos comparativos de países que, ao longo do período indicado, foram se livrando de suas autocracias.

Destacam-se quatro qualidades distintivas fundamentais da abordagem transitológica.

a) Em primeiro lugar, e talvez como ponto crucial, observa-se uma ruptura com o padrão estrutural-funcionalista prevalecente nos estudos sobre "modernização". 9 A transitologia, em seu sentido mais próprio, é uma espécie de reação a um padrão de análise que adquirira hegemonia nos estudos sobre democracia e desenvolvimento após a segunda grande guerra. As mudanças sociais, objeto precípuo destas todas disciplinas, não mais seriam observadas por meio de padróes históricos de cunho econômico e social na longa duração. A ruptura epistemológica que se produz jogava para o centro da cena uma ideia de transição que, por suas características altamente particulares, não poderia jamais ser reduzida a tais causalidades: a transição era aquilo que se furtava à padronização e suspendia, temporariamente, a influência primária das restriçóes e condicionantes econômico-sociais. Nas palavras de Gabriel Vittulo,

9 Confrontar com o trabalho de Nils Gilman (2003). 
Como forma de justificar essa mudança epistemológica, sobretudo por parte daqueles que no passado aderiam ao estruturalismo - como é o caso, citando só um exemplo, de Guillermo O’Donnell -, a nova corrente alega a necessidade de um excepcionalismo metodológico, o que configura outro de seus elementos caracterizadores. Os autores que aderem ao novo paradigma justificam-no pelo excepcional das próprias situaçóes sob estudo; consideram que as ciências sociais normais têm sido pensadas para períodos de estabilidade política e, conseqüentemente, não serviriam para analisar mudanças de regime, transiçóes ou períodos de crises agudas. (...)Em tais circunstâncias, para a transitologia e de acordo com o que expressa Dobry, não existem determinismos nem causalidades estruturais. (VITULLO, 2001, p. 54).

Esse é o caminho teórico que seguirá a transitologia desde as pegadas de Rustow, para quem as explicaçóes puramente funcionais não davam conta do fato de que "[n] em todos liames causais fluem do social e do econômico para o político" (1970, p. 346). ${ }^{10}$ A escolha de uma teoria da ação para a compreensão da mudança social enceta uma abordagem volitiva de tais processos. Isso significa, por um lado, focalizar em quem pode agir através de uma identificação das elites políticas; por outro, restringir a “(...) questão da mudança social àquela da transformação legal-institucional - ao inverso daquela estrutural - que pode ser atribuída a agentes específicos" (GUILHOT, 2002, p. 235). ${ }^{11}$

b) A transitologia privilegia um modelo de ação centrado na contingência de interaçóes e na incerteza constitutiva que caracteriza as escolhas de elites políticas ao longo de processos transicionais. Leonardo Avritzer criticou muito bem a maneira como, mesmo pretendendo romper com uma tradição anterior de elitismo nos estudos democráticos, a teoria das transiçóes democráticas acabou preservando a dicotomia fundamental entre elites e massas. É evidente que, ao contrário de autores como Joseph Schumpeter e Anthony Down, as elites políticas não são mais entendidas como a salvaguarda de uma racionalidade democrática em face do perigo irracional de uma participação política das massas. Aqui a participação popular é vista como componente de um processo de democratização, mas jamais como elemento suficiente. Em outras palavras, as massas ocupam, na transitologia, o papel de possíveis influências e pressões sobre as elites que, por sua vez, têm o condão de optar definitivamente pela democracia.

Por um lado, [a teoria das transiçóes democráticas] rompe, ao notar que a ação coletiva pode fortalecer os valores democráticos, com a concepção democrático-elitista de que a mobilização das massas é anti-democrática. Por outro lado, ela ainda concebe a mobilização de massas no interior do arcabouço mais amplo de uma relação elitemassas: mobilizaçóes de massa não desempenham um papel democratizante per se, mas muito mais um papel coadjuvante no processo interno de negociaçóes entre elites. Com efeito, a ruptura da teoria da transição com o elitismo democrático é parcial, devido a sua incapacidade de compreende por completo o papel dos movimentos sociais na democratização da América Latina (AVRITZER, 2002, p. 29). ${ }^{12}$

10 No original: "Not all causal links run from social and economic to political factors".

11 No original: "(...) question of social change to that of legal-institutional - rather than structural - transformations that can be attributed to specific agents".

12 No original: "On the one hand, it breaks with the democratic elitist assumption that mass mobilization is anti-democratic 
Essa ideia se concretiza na aposta de Huntignton de que as melhores chances de consolidação democrática residem num pacto bem realizado entre as elites reformistas do grupo governista e as elites moderadas do grupo oposicionista. É dele a formulação mais clara: "[n] egociaçóes e compromisso entre elites políticas formavam o núcleo dos processos de democratização”. (HUNTIGNTON, 1991, p. 165). ${ }^{13}$

c) A transitologia propóe, ainda, uma versão das mudanças sociais centrada nas instituiçóes jurídico-políticas. Partindo da premissa de que o que havia causado o recuo da "segunda onda de democratizaçóes" (1943-62) teria sido uma ausência de suficiente institucionalização dos procedimentos democráticos, a teoria das transiçóes pretende abordar agora este componente como conditio sine qua non de qualquer processo democratizante. Este náo é mais que um desdobramento da opção por uma teoria da ação somada à opção elitista. Guilhot e Schmitter não deixam grandes dúvidas a este respeito quando definem o escopo da análise da forma que se segue.

Convém observar, entretanto, que a distinção que se opera entre as normas e a função socializante das normas é puramente analítica, uma vez que só se pode definir uma instituiçẫo por suas normas à medida que elas efetivamente regulam o comportamento dos agentes institucionais. Elas não possuem vida própria para além de sua expressão atitudinal e material. (GUILHOT; SCHMITTER, 2000, p. 616). ${ }^{14}$

As instituições legais conformam os atributos objetivamente identificáveis do sucesso ou não da passagem à democracia, simbolizando a solução das disputas políticas com respeito às regras do jogo. "Ou, como colocou Rustow, a criaçáo da democracia requer que as elites cheguem a 'um consenso procedimental sobre as regras do jogo"”. (HUNTINGTON, 1991, p. 36). ${ }^{15}$

d) Consequentemente, vê-se o desenhar de uma teleologia anistórica cujo ideal regulador - no sentido Kantiano de um uso regulador de ideias que representam um horizonte além dos limites da experiência possível (KANT, p. 426) - é representado por uma versão institucional e asséptica de democracia ocidental. As teorias da transição democrática precisam se valer da noçáo de consolidação para preencher de sentido o significante "democracia". Na acepção sintética de Adam Przeworski - talvez a mais conhecida formulação que se liga a este conjunto de estudos -, "a democracia está

by noting that collective action might strengthen democratic values. On the other hand, it still conceives mass mobilization within the broader framework of an elite-masses relationship: mass mobilizations do not play a democratizing role per se, but rather an adjuvant role in the internal process of negotiation among elites. Thus, transition theory's rupture with democratic elitism is partially due to its inability to understand fully the role of social movements in Latin American democratization".

13 No original: "Negotiations and compromise between politcal elites were at the heart of the democratization process".

14 No original : "Il convient observer cependant que la distinction que on opère entre les normes et la fonction socialisante des normes est purement analytique car on ne peut définir une institution par ses normes que dans la mesure où elles régulent effectivement le comportement des agents institutionnels. Elles ont pas de vie propre en dehors de leur expression attitudinale et matérielle".

15 No original: "Or, as Rustow put it, the creation of democracy requires that elites arrive at a 'procedural consensus on the rules of the game". 
consolidada quando, sob dadas condiçóes políticas e econômicas, um particular sistema de instituições se torna o único jogo na cidade." (PRZEWORSKI, 1991, p. 26). ${ }^{16}$

Este modelo de democracia servirá de ideal regulador para toda a composição teórica e política da transitologia. Ele figurará no horizonte a um só tempo como limite e como inevitabilidade histórica, ainda que nem sempre os autores o admitam. A noção de transição não deixa jamais de preservar certa escatologia liberal como componente organizador de sua racionalidade interna. Uma vez que a democracia resida ao final de um processo histórico inelutável, qualquer prescrição pode ser diluída num fantasmático descrever neutro. Citando Linz e Huntignton, dirá Guilhot:

Este entendimento jamais fora mais perfeitamente claro do que com o colapso do comunismo na Europa do Leste. Como resultado, os processos de transição para a democracia foram vistos como inseridos numa tendência histórica mais ampla que culmina em instituiçóes políticas e econômicas de cariz liberal e ocidental. Essa teleologia histórica, portanto, atribuía significado e direção predeterminados a esses eventos (GUILHOT, 2002, p. 238). ${ }^{17}$

Tal escatologia enceta as bases do argumento que interessa a este artigo, a saber, a relação entre transição e história. Mais precisamente, pode-se dizer que a transitologia e, neste caso, sua impreterível conjunção com uma consolidologia - é incapaz de lidar com o acontecimento, isto é, com a chegada de um outro inantecipável.

e) A transitologia desenvolve em seu interior um modelo de abstração/neutralização capaz de oferecer tipos genéricos que prevaleçam sobre as manifestaçóes concretas dos inúmeros casos estudados. Estes estudos se colocaram a tarefa de observar uma gama imensa de casos concretos que abundam em especificidades e idiossincrasias. Entretanto, por vias de um esforço analítico, este objetivo pode ser cumprido se forem preservados os elementos invariáveis capazes de sustentar a gênese de uma tipologia - próximo aqui ao sentido weberiano de Idealtypus (WEBER, 1995). Francisco Weffort oferece uma caracterização arquetípica ao tratar da ideia de novas democracias:

O principal objetivo desta linha de análise é identificar uma gama potencial de situações empíricas, bem como desenvolver uma capacidade analítica para desvelar variedades de híbridos, graus de hibridização e similares. (WEFFORT, 1993, p.28). ${ }^{18}$

Vitullo também criticará duramente as excessivas generalizações e abstrações de um modelo politicista de análise das mudanças sociais. Para ele, abordagens como essas “impediram uma observação e análise mais aguçada das singularidades de cada caso

16 No original: "Democracy is consolidated when under given political and economical conditions a particular system of institutions become the only game in town".

17 No original: "This understanding has never been more clear-cut than with the collapse of communism in Eastern Europe. As a result, the processes of transition to democracy have been seen as embedded in a broader historical trend that culminates in Western liberal political and economic institutions".

18 The principal objective of this line of analysis is to identify a potential range of empirical situations as well as to develop an analytical capacity for uncovering varieties of hybrids, degress of hybridization, and the like. 
nacional e dificultaram, também, uma melhor avaliação do tipo de democracia que ia se configurando em cada um deles" (VITULLO, 2001, p. 56).

A simplificação desmedida remete a uma aporia interna ao discurso da teoria das transições democráticas. Por um lado, as transiçóes representam o esforço de ruptura com um modelo de explicação da mudança social baseado na causalidade de estruturas econômico sociais. Passa-se a dar privilégio, como já fora descrito anteriormente, à categoria da ação. A transição assim enxergada, portanto, lança a análise no reino da aleă, da ação humana que não pode ser maquinalmente antecipada e regulada. Há, e os autores da transitologia em geral são os primeiros a reconhecê-lo, um elemento de incontornável incerteza que anima este domínio e, sua consequência, é que qualquer resultado será contingente, não-necessário, indeterminado. Por outro lado, a própria teoria se apresenta como tentativa de neutralização desta via analítica; ela é a busca incessante de reduzir os acontecimentos a dados anistóricos e descontextualizados de um léxico puramente formal: o paradoxo reside na tentativa de regrar aquilo que se furta às regras, condicionar o que não pode ser condicionado. Guilhot e Schmitter chegam a uma conclusão similar quando dizem que:

O conceito de transição coloca em relevo a natureza dos regimes políticos, no sentido de que eles formalizam a mudança política sob a base de procedimentos que definem tipos genéricos [...]. Deste ponto de vista, o tipo genérico prevalece sobre as configuraçóes concretas, o tipo ideal sobre a realização concreta de um conjunto de instituiçóes. (GUILHOT; SCHMITTER, 2000, p. 618). ${ }^{19}$

A pergunta que se deve fazer não diz tanto respeito à viabilidade de tal formulação; nem sequer à sua utilidade em face de modelos descritivos concorrentes. A verdadeira questão que emerge deve ser: o que se perde? O que está sendo deixado de lado no conjunto destas neutralizaçóes? Qual o sentido implícito de uma abordagem que faz o tipo ideal prevalecer sobre o concreto?

O que é a perda do concreto? Náo seria ela, precisamente, a perda do elemento fundamental de dação de sentido? Aquilo que permite aos participantes de tais processos atribuírem-lhe significado e, sobretudo, vivenciá-lo em sua semântica inesgotável? De um ponto de vista interno às próprias práticas, não seria o concreto o elemento que desafia a preponderância de um acordo entre elites e transforma a ação política em elemento imponderável, inantecipável e irreprimível? Paulo Sérgio Pinheiro escrevia em 1991 que "quem já viveu sob uma ditadura ou regime autoritário não tem dúvidas, quando a opressão termina, de que efetivamente mudanças ocorreram" (1991, p. 47). Pergunta-se: de onde surge esta certeza senão da imersão na concretude das práticas sociais? Quando se deixa de lado o concreto, a história não mais importa. Seu papel não é mais que aquele de

19 No original : "Le concept de transition met en relief la nature des régimes politiques, au sens où il formalise le changement politique sur la base des procédures définissant des types génériques (...). De ce point de vue le type générique prévaut sur les configurations concrètes, idéal type sur sa réalisation dans un ensemble concret institutions". 
um elemento coadjuvante no processo de consolidação democrática prescrito pela teoria da transição democrática. A insegurança e a instabilidade, pedras de toque do estatuto epistemológico da disciplina, eram condiçóes de possibilidade somente sob a condição de serem também o quid a ser evitado, reduzido, limitado. A história, enquanto constituição do contexto, é objeto manipulável inserido numa pura relação de instrumentalidade. A racionalidade puramente instrumental não é capaz de perceber que a história, entendida em seu estatuto mais radical, desempenha um papel constitutivo da gênese do sentido. ${ }^{20}$

Justamente porque a história é algo mais do que um mero contexto (em seu sentido analítico restritivo) é que ela adquire relevância para a compreensão das transiçóes políticas. Sem esse elemento, noçôes como legitimidade, constitucionalismo, direitos fundamentais, justiça e mudança social náo podem ser preenchidas de sentido, posto que destacadas das condiçóes de possibilidade de dação de significado.

O lugar reservado à história na tradição da transitologia coloca em risco aquilo que ela pretendia defender, ou seja, a democracia. A questão passa a ser a seguinte: como a justiça de transição herda essa abordagem?

\section{Uma história que pertence ao Direito?}

A leitura feita ao início deste artigo supóe que, ao menos na proposta inicial organizada por Kritz, a história permanece sendo entendida do mesmo modo que o fora pela transitologia. Entretanto - e essa é uma questão que não pode jamais ser perdida de vista -, a justiça transicional não se reduz às intenções originais de Kritz, tampouco às propostas e debates que hoje, no interior da disciplina, são vistas como contendo um papel fundante. Extrai-se daí a conclusão de que uma análise séria da relação entre transitional justice e história depende de investigação mais aprofundada.

$\mathrm{Na}$ coletânea de artigos publicada sob o título Transitional justice from below, trabalho que, seguramente, adquiriu status de obra imprescindível para o campo da justiça de transição, é colocado em xeque este padrão de análise abstrato que prescreve soluçóes pré-produzidas - “'off-the-shelf” models”, como bem colocam McEvoy e McGregor (2008, p. 2). Manejando um léxico que gravita ao redor de uma ideia crítica de comunidade contextual, histórica, basilar -, o volume propóe-se a revisar criticamente o modo asséptico como a justiça transicional, seja em sua versáo internacionalizada ou nacionalizada, tem lidado com elementos populares nas transições. O sintagma from below (a partir de baixo) busca apreender esta tentativa de reorientação teórico-metodológica que pressupóe que

20 Ao propor sua distinção do filosofar analítico e do filosofar hermenêutico, o filósofo argentino Julio Cabrera escreve: "Tanto a história efetual gadameriana quanto a pré-compreensão originária de Heidegger, ou a Lebenswelt husserliana, não constituem apenas 'contextos de uso' de proferimentos, mas grandes marcos de inteligibilidade que as próprias expressóes 'contextualizadas' devem sempre supor' (CABRERA, 2003, p. 62). 
[...] frequentemente são as vítimas e sobreviventes, organizaçóes comunitárias e da sociedade civil, organizaçóes não-governamentais de direitos humanos, organizaçóes eclesiásticas e outros que têm sido o motor da mudança. (McEVOY; McGREGOR, 2008, p. 3). ${ }^{21}$

Nota-se, de início, a radical contraposição ao elitismo que caracterizou a transitologia. Se a abordagem from below preserva seu fulcro num modelo de ação, o sujeito privilegiado é completamente alterado.

Entretanto, o que interessa aqui, por ora, é compreender a razão de sua crítica à tendência hegemônica no interior da justiça transicional. McEvoy (2008, p. 19 et seq.) argumenta, em termos amplos, que uma versão do positivismo legalista adquiriu completa hegemonia no campo da justiça transicional. Esta tendência toma a forma de um tripé, baseado em: a) legalismo como sedução, isto é, a ideia de que a construção de um Rule of Law é suficiente para reconstruir sociedades arrasadas por conflitos armados ou governos autoritários; b) o triunfo dos direitos humanos como o triunfo de valores universais a despeito dos valores locais; c) o "enxergar como um Estado", descrevendo a tendência de pensar a justiça de transição da perspectiva estatal, de suas instituiçôes formais.

Sem cometer nenhum reducionismo extravagante, pode-se muito bem dizer que as críticas sublinhadas acima são, em larga medida, idênticas àquelas que descrevemos ao encontro da transitologia - tratadas no item anterior deste artigo. Elitismo, institucionalismo, abstracionismo. A justiça transicional from above (a partir de cima), é denunciada como a tentativa de aplicação genérica de um modelo que se pretende universal.

As críticas desenhadas em Transitional justice from below compóem um movimento ocorrido no interior da disciplina que, a partir sobretudo do final dos anos 2000, buscou colocar em questão o caráter acentuadamente liberal da justiça de transição (NAGY, 2008; SRIRAM, 2009; PFEIFFER, 2014). Um dos alvos primordiais dessa crítica é Ruti Teitel, autora do célebre Transitional justice. Teitel é não apenas uma das principais defensoras de um modelo de justiça transicional compreendido como transição para uma democracia liberal; ela é também a autora que mais tenha se dedicado a desenvolver os contornos conceituais do campo em suas implicações políticas, jurídicas e filosóficas. Ao cunhar o termo "justiça de transição" em 1991 (TEITEL, 2008), Teitel se preocupou em evidenciar os aportes herdados da transitologia, mas buscou igualmente evidenciar as demarcações teóricas entre as duas disciplinas. O problema do "concreto" e do recurso a categorias abstratas a convenceu da necessidade de pensar um outro método:

A Justiça Transicional adota um método amplamente indutivo e, explorando o conjunto de respostas jurídicas, descreve uma concepção distinta de direito e justiça no contexto de transformaçôes políticas. A Justiça Transicional começa ao rejeitar a noção de que o

21 No original: it is frequently victims and survivor groups, community and civil society organisations, human rights nongovernmental organisations, church bodies and others that have been the engines of change. 
movimento em direção a um sistema político mais liberal e democrático implica uma norma universal ou ideal. (TEITEL, 2000, p. 4, grifos meus). ${ }^{22}$

E, mais adiante, no momento de esboçar uma teoria da justiça de transição:

A perspectiva histórica e comparativa adotada aqui sugere que aquilo que é julgado verdadeiro e justo em períodos de transição é politicamente contingente, mas não num sentido arbitrário. Apesar das pretensões realistas, uma fenomenologia transicional não é simplesmente o produto de persistentes circunstâncias políticas, mas é, ao contrário, uma função de circunstâncias políticas contemporâneas e de legados históricos de injustiça. (2000, p. 223 , grifos meus). ${ }^{23}$

Os termos e expressóes destacados em negrito atestariam um abismo entre a proposta de Teitel e aquela formulada pelas teorias da transição. A perspectiva histórica parece adquirir centralidade em seu pensamento, ao lado de um método indutivo que exige uma contextualização imune a toda pulsão de universalização e abstração. Em grande medida, essa visão da história parece acompanhar a crítica que O’Donnell faria, já na década de 90, a sua própria noção de consolidação. Dizia ele não saber se a transitologia abordava uma "[...] média de características observadas no conjunto das antigas poliarquias, um tipo ideal gerado a partir de algumas características, uma generalização do conjunto de características de alguns membros ou um esboço de preferências normativas" (1996, p. 38). ${ }^{24}$ Notava O’Donnell ali um “[...] aroma fortemente teleológico” (1996, p. 38). ${ }^{25}$ Enunciar a crítica, contudo, não significa realizá-la. Um olhar mais aprofundado poderá ver entre a Transitional Justice de Teitel e a transitologia uma série de confluências e congruências. O ponto central, uma vez mais, reside menos no emprego da "história" e mais no valor a ela atribuído.

Teitel lança as bases definitivas da composição teórica do campo da justiça de transição ao recobri-lo de uma teoria. Se, como se dizia acima, Kritz é o organizador das temáticas tratadas pela justiça transicional, Teitel dá a elas um estatuto de independência epistemológica. Essa independência surge da ideia de que o direito não é apenas um elemento de composição da consolidação democrática forjado pela maneira como a transição é realizada; agora, seu papel é muito mais central e inclui refletir sobre o modo como o direito influi decisivamente na transição ela própria. Entretanto, o paradigma transicional não é contestado quanto à sua orientação teleológica. A consolidação continua

22 No original: "Transitional Justice adopts a largely inductive method, and, exploring an array of legal responses, it describes a distinctive conception of law and justice in the context of political transformation. Transitional Justice begins by rejecting the notion that the move toward a more liberal democratic political system implies a universal or ideal norm".

23 No original: "The comparative and historical perspective adopted here suggests that what is deemed true and just in transitional periods is politically contingent but not in an arbitrary sense. Despite realist claims, transitional phenomenology is not simply the product of its abiding political circumstances but is, instead, a function of contemporary political circumstances and historical legacies of injustice".

24 No original: “(...) an average of characteristics observed within the set of old polyarchies, or an ideal type generated from some of these characteristics, or a generalization to the whole set of the characteristics of some of its members, or a normative statement of preferred traits".

25 No original: “(...) a strong teleological flavor”. 
a funcionar como uma escatologia; a transição opera como um recorte temporal limitado pelos agentes; permanece o grande interesse pelas instituiçóes, agora não mais políticas, mas jurídicas; resta um ranço elitista, alterando-se o foco das elites políticas moderadas para as elites judiciárias (nacionais e internacionais); e, finalmente, o autoritarismo é caracterizado como ruptura da Rule of Law e a democratização como constituição desta mesma Rule of $L a w .{ }^{26} \mathrm{O}$ que chama a atenção, em verdade, é a presença de uma relação aporética de Teitel com o arcabouço teórico da transitologia: por um lado uma ruptura com seus pressupostos, com seus anseios, com seus filosofemas; por outro, a utilização instrumental de suas categorias, o tomar-parte em seus conceitos.

O terceiro capítulo de Transitional Justice, dedicado à relação entre transição e história, é bastante indicativo da aporia que se quer demonstrar. Ali, Teitel demonstra que conhece certa bibliografia contemporânea de história social, pinçando aquele que lhe parece ser o ponto fulcral da questáo: fundar a democracia num pano de fundo comum compartilhado de sentido. A autora esclarece que, sem essa passagem, não é possível romper definitivamente com o regime autocrático anterior: é necessário que se criem mecanismos de construção de história comum que possam reler criticamente o legado de autoritarismo. Apropriando-se reconstrutivamente das liçóes da Aufklärung, Teitel afirma que a ciência histórica passou por um giro interpretativo, no qual “(...) não há um simples, claro e determinado entendimento ou 'lição' a ser retirada do passado, mas, em seu lugar, reconhece-se o grau em que a compreensão histórica depende de contingências políticas e sociais" (2000, p. 70) ${ }^{27}$ Rejeita-se, inclusive, a noção de fundação, posto que a história é construída sob um background coletivo que se baseia na memória de narrativas anteriores. Há um estreitamento entre política e história em períodos de grave comoção social tendentes a uma mudança de regime e, não por outra razão, Teitel dirá que “[m] udanças em regimes políticos, deste modo, significam correlatas mudanças em regimes de verdade.” (2000, p. 70). ${ }^{28} \mathrm{O}$ problema está posto de modo inequívoco: como sociedades que passam por uma ruptura político-social podem formar consensos mínimos de verdade a fim de preencher novamente de significado o conjunto de suas interações. É precisamente este o dilema colocado ao longo deste artigo e usado para contrapor-se à abordagem a-histórica da transitologia e de parte da justiça transicional.

Entretanto, no exato momento em que chega a esta conclusão, Ruti Teitel dá um passo atrás: volta com força às limitaçóes impostas pelo paradigma da transição ao reenquadrar o dilema exposto numa análise institucional do direito. $\mathrm{O}$ argumento tem duas etapas. Em primeiro lugar, Teitel parte da premissa que o corpo social é desfeito nos momentos de transição política, desfazendo-se os marcadores sociais de consenso.

26 Deve-se atentar contudo para o fato de que, em Teitel, a Rule of Law contém maior elasticidade, recebendo diferentes significados de acordo com os abusos anteriores e as respostas oferecidas (TEITEL, 2000, p. 19).

27 No original: (...) there is no single, clear, and determinate understanding or "lesson" to draw from the past but, instead, recognition of the degree to whichhistorical understanding depends on political and social contingency.

28 No original: "Changes in political regimes, accordingly, mean attendant changes in truth regimes". 
Sem tais arcabouços, apenas o direito é capaz de sinalizá-los a contento. "Na transição, os arcabouços compartilhados normalmente - políticos, religiosos, sociais - estão ameaçados; portanto, é o direito, seu arcabouço e processos que, em grande medida, dão forma à memória coletiva" (2000, p. 71) ${ }^{29}$. Do fato de que vários loci de debate público e entendimento se encontram ameaçados não decorre a conclusão imediata de que o direito perfaz o lote último de significação histórico-memorial. No momento da transição, ele também se encontra em frangalhos.

Esta, contudo, não é a opinião de Teitel, para quem “[n]as transições, o papel primordial na formação da memória social é desempenhado pelo direito”. (2000, p. 71). ${ }^{30}$ Não se pretende aqui menosprezar o papel dos procedimentos jurídicos - metonimizados, em grande medida, pelos grandes processos criminais - na composiçáo do que se espera ser a memória do autoritarismo ou a história do ancien régime. Eles têm sim seu lugar e este é um lugar de relevo. Entretanto, a pergunta correta deve-se dar no interior da aporia entre "o que o direito faz para compor a história?" e "o que a história faz para preencher de significado o direito?". Sem a tensão permanente entre as duas dimensôes, sem a dialética sem síntese possível entre as duas, assume-se não apenas que a história pode ser confinada pela juridicidade, mas, sobretudo, que uma elite judiciária pode dela se apoderar.

\section{Conclusáo}

Este artigo se interessou pelas relações entre Justiça de Transição e história. Se em Neil Kritz a imagem anistórica das transiçôes políticas parecia quase imediata, viu-se que, em Ruti Teitel, este problema se complexifica diante da tarefa de superar a transitologia por via da justiça de transição. A despeito de seus esforços, Teitel continua a atribuir à história um cariz instrumental e não constitutivo-existencial. Assumiu-se aqui que este é um padrão de análise arriscado. Por um lado, ele não permite que se previnam os abusos no uso da história, em especial no que se refere a uma elite do judiciário que obteria privilégio na determinação e fixação do passado. Foi este precisamente o caso vivido no Brasil em razão da Ação de Descumprimento Fundamental 153, na qual o Supremo Tribunal Federal encampou a tese de uma transição pactuada, dominada pelos grandes atores políticos e fundada em um regime geral de esquecimento.

Entre "transitologia" e "justiça de transição", impera o modelo de uma história controlada e tendente a gerar resultados ótimos em termos de consolidação democrática. O problema, como apontamos, é que a noção de "consolidação" se esvazia completamente neste quadro, tornando-se um modelo abstrato composto de tipos ideais vazios. Reduzida a essa escatologia liberal, a democracia se transforma em jogo de elites, espécie

29 No original: "In transition, the oft-shared frameworks—political, religious, social—are threatened; so it is the law, its framework, and processes that in great part shape collective memory".

30 No original: "In transitions, the pivotal role in shaping social memory is played by the law". 
de oligarquia na qual direitos fundamentais são obliterados para compor um equilíbrio político de baixa intensidade democrática.

É preciso, talvez, pensar uma reorientação hermenêutica destes debates, levandose em consideração os mecanismos institucionais de condensação entre história e direito. Seria interessante indagar, por exemplo, se a forma-constitucional é condição necessária para a articulação entre memória e projeto no seio de democracias que experimentaram transiçóes políticas. Isso significa, entre outras coisas, investigar os direitos fundamentais que foram indevidamente negociados em nome de um conceito específico de anistia. Memória e tempo histórico devem ser, aqui, um retorno aos corpos desaparecidos e torturados, às ideias reprimidas, às pessoas e organizaçóes perseguidas. Entre transição e história, articula-se algo maior que a simples fixação das regras do jogo político (como na transitologia): trata-se da elaboração de um pano de fundo compartilhado quanto ao projeto de democracia que sustenta uma comunidade política.

\section{Referências}

ARTHUR, Paige. How "transitions" reshaped human rights: a conceptual history of transitional justice. Humans Rights quarterly, v. 31, p. 321-367, 2009.

ASH, Timothy Garton. The truth about dictatorship. New York Review of Books, New York, 19 fev. 1998. Disponível em: http://www.nybooks.com/articles/archives/1998/ feb/19/the-truth-about-dictatorship. Acesso em: 26 jun. 2018.

AVRITZER, Leonardo. Democracy and the public space in Latin America. Princeton: Princeton University Press, 2002.

AVRITZER, Leonardo; COSTA, Sérgio. Teoria crítica, democracia e esfera pública: concepçóes e usos na américa latina. Revista de Ciências Sociais, Rio de Janeiro, v. 47 (4), p. 703-728, 2004.

BELL, Christine. Transitional Justice, Interdisciplinarity and the state of the 'field' or 'non-field'. The international journal of transitional justice, v. 3, p. 5-27, 2009.

BOURDIEU, Pierre. Le sens pratique. Paris: Éditions Minuit, 1980.

CABRERA, Julio. Margens das filosofias da linguagem. Brasília: Ed. UnB, 2003.

GUILHOT, Nicolas. The transition to the human world of democracy notes for a history of the concept of transition, from early marxism to 1989. European Journal of Social Theory, v. 5(2), p. 219-243, 2002. 
GUILHOT, Nicolas; SCHMITTER, Philippe. De la transition à la consolidation. Une lecture rétrospective des democratization studies. Revue française de science politique, $\mathrm{v}$. 50(4-5), p. 615-632, 2000.

HUNTIGNTON, Samuel. The third wave: democratization in the late twentieth century. Norman: University of Oklahoma Press, 1993

KANT, Immanuel. AA III. Kritik der reinen Vernunft. Berlin : de Gruyter, 1968-77.

KRITZ, Neil J. The dilemmas of transitional justice. In: KRITZ, Neil J (Org.). Transitional Justice: how emerging democraties reckon with former regimes. Washignton, DC: United States institute of peace, 1995.

LINZ, Juan; STEPAN, Alfred. Problems of democratic transition and consolidation: Southern Europe, South America and Post-Communist Europe. Baltimore: The John Hopkins University Press, 1996.

McEVOY, Kieran; McGREGOR, Lorna (Orgs.). Transitional justice from below: grassroots activism and the struggle for change. Oxford: Hart Publishing, 2008.

MÉNDEZ, Juan E. Editorial Note. The international journal of transitional justice, v. 3, p. $157-152,2009$.

NAGY, Rosemary. Transitional Justice as a Global Project: Critical Reflections. Third World Quarterly, 29(2), p. 275-289, 2008.

NOLTE, Ernst. Die Vergangenheit, die nicht vergehen will. Eine Rede, die geschrieben, aber nicht gehalten werden konnte. FAZ, 6 jun., 1986. Disponível em: http://www.hdg.de/lemo/html/dokumente/NeueHerausforderungen_redeNolte1986/ index.html. Acesso em: 26 jun. 2018.

O’DONNELL, Guillermo et al. (Orgs.). Transition from authoritarian rule: comparative perspectives. Baltimore: The John Hopkins University Press, 1986.

O’DONNELL, Guillermo. Illusions about consolidation. Journal of Democracy, v. 7(2), p. 34-51, 1996.

O'DONNELL, Guillermo; SCHMITTER, Philippe. Transitions from authoriarian rule - tentative conclusion about uncertain democracies. Baltimore: The Johns Hopkins University Press, 1986.

PINHEIRO, Paulo Sérgio. Autoritarismo e transição. Revista USP, n. 9, p. 45-56, 1991.

PRZEWORSKI, Adam. Democracy and the market. Cambridge: Cambridge University Press, 1991. 
RUSTOW, Dankwart A. Transitions to Democracy: Toward a Dynamic Model. Comparative Politics, v. 2(3), p. 337-363, 1970.

SALLUM JÚNIOR, Basílio. Transição política e crise do Estado. Lua Nova, v. 34, p. 133-167, 1994.

SRIRAM, C. L. Transitional Justice and the Liberal Peace. In: NEWMAN, E. et al. (Orgs.). New Perspectives on Liberal Peacebuilding. Tokyo: United Nations University Press, 2009.

TEITEL, Ruti G. Transitional justice. New York: Oxford University Press, 2000

TEITEL, Ruti. Editorial note-transitional justice globalized. The International Journal of Transitional Justice, v. 2, p. 1-4, 2008.

TEITEL, Ruti. Transitional Historical Justice. In: MEYER, Lucas H (Org.). Justice in time: responding to historical injustice. Baden-Baden: Nomos, 2004.

VITULLO, Gabriel E. Transitologia, consolidologia e democracia na América Latina: uma revisão crítica. Revista de Sociologia e Politica, v. 17, p. 53-60, 2001.

WEBER, Max. Die Objektivität sozialwissenschaftlicher und sozialpolitischer Erkenntnis. Tübingen: Wissenschaftlicher Verlag, 1995.

WEFFORT, Francisco C. What is a 'new democracy'? International Social Science Journal, v. 45(2), p. 245-56, 1993. 